\title{
Formation of Assimilable Organic Carbon from Algogenic Organic Matter
}

\author{
Ji Hoon Kim ${ }^{1 \dagger}$, Soon-Hyung Chung ${ }^{2}$, Jing-Yeon Lee ${ }^{2}$, In-Hwan Kim², Tae-Ho Lee ${ }^{2}$, Young Ju Kim \\ ${ }^{1}$ Department of Environmental Engineering, Kyungpook National University, Sangyeok-dong 3-ga, Buk-gu, Daegu 702-701, Korea \\ ${ }^{2}$ Department of Health Environment, Daegu Health College, Taejeon-dong 1-ga, Bukgu, Daegu 702-722, Korea
}

Received July, 2009 ; Accepted January, 2010

\begin{abstract}
The objective of this study was to assess the variation in the concentration of assimilable organic carbon (AOC) in a drinking water resource, and investigate the characteristics of AOC derived from algae. The seasonal change in AOC at the Kamafusa dam corresponded to changes in the algal cell number. In order to understand the relationship between AOC and algae in a water resource and water purification plant, two kinds of laboratory experiment were performed. The algal culture experiment showed that extracellular organic matter (EOM) that was released during the growth of Phormidium tenue with M-11 medium led to significant increases in the AOC concentration, but no significant variation in the AOC concentration was observed with CT medium containing a high dissolved organic carbon concentration. The chlorination experiment showed that the AOC included in EOM was not easily removed by chlorination, although the AOC included in intercellular organic matter released from the algal cells by chlorination was removed under conditions where residual chlorine was detected.
\end{abstract}

Keywords : Assimilable organic carbon, Chlorination, Extracellular organic matter, Intercellular organic matter

\section{Introduction}

To maintain the quality of drinking water from a water purification plant to the supply taps is very important. In order to achieve this, residual chlorine is essential, and the multiplication of bacteria must be suppressed. However, heterotrophic bacteria are known to adhere to the inner surface of pipes, where they proliferate and form biofilms under the condition without residual chorine[1, 2]. The regrowth of bacteria and detachment of biofilms would cause a deterioration of in the quality of water in the distribution system. Some bacteria in biofilms are known to not be eliminated by chlorine disinfection[3-5]. Generally, bacterial regrowth is associated with assimilable organic carbon (AOC). Van der Kooij et al.[6], Escobar and Randall[7] suggested AOC should be less than $10 \mu \mathrm{g} / \mathrm{L}$ to limit the growth of heterotrophic plate counts (HPCs) of bacteria in un-chlorinated systems. Therefore, the reduction of AOC is also an important measure for the control of bacterial regrowth. In Japan, interest has not focused on the reduction of AOC, since the maintenance of residual chlorine successfully controls bacterial regrowth. However, the reduction of AOC may be effective in both reducing the chlorine dose and controlling bacterial regrowth. There have been many investigations on the behavior of AOC in water purification systems. The concentration of AOC is difficult to control using conventional drinking water treatment processes[8,
$9,10]$. Conversely, there have only been a few studies on the behavior of AOC in water resources. Especially, the effect of eutrophication on the behavior of AOC is unclear, although eutrophication significantly affects water purification processes. In addition to the presence of dissolved natural organic matter (NOM), surface water, such as lakes, is subject to seasonal algal blooms, which can contribute significantly to the organic carbon load in drinking water treatment systems[11]. Algogenic organic matter (AOM) is not easily chemically and biologically degraded. Blooms of blue-green algae or diatoms cause difficulties in controlling dissolved organic carbon (DOC) because of the release of extracellular AOM (EOM) into water, as well as the release of intracellular AOM (IOM) by cell lysis. Algae and EOM can be precursors for disinfection by-products (DBP). The existence of AOM composed of glycolic acid, carbohydrate, amino acid and organic phosphorus etc might cause an increase in the AOC concentration[12-15].

This study was performed in order to examine the variation in the AOC concentration at a drinking water resource, and discover the characteristics of AOC derived from algae. The seasonal

\footnotetext{
+Corresponding author

E-mail: kimjihoon@knu.ac.kr

Tel: +82-53-950-7896, Fax: +82-53-950-7897
} 
changes in the AOC concentration in the Kamafusa dam, the main reservoir of Sendai city, Japan, and three inflowing rivers were investigated. The influence of algae on the AOC concentration was studied via a series of experiments; (1) to assess the generation of AOC derived from the EOM of the bluegreen alga, Phormidium tenue, under different culture medium conditions, and (2) to assess the formation and the removal of AOC derived from the EOM and IOM due to chlorination.

\section{Materials and Methods}

\subsection{Study Sites}

Sample waters were taken from the Kamafusa dam and the three rivers; Taro, Kita and Mae, as shown in Fig. 1. The Kamafusa dam is one of the main drinking water resources in Sendai city, which the three rivers flow into. The end product after the water purification plant process of the Kamafusa dam was also sampled. Sampling was carried out once in about 2 months over a 14 month period.

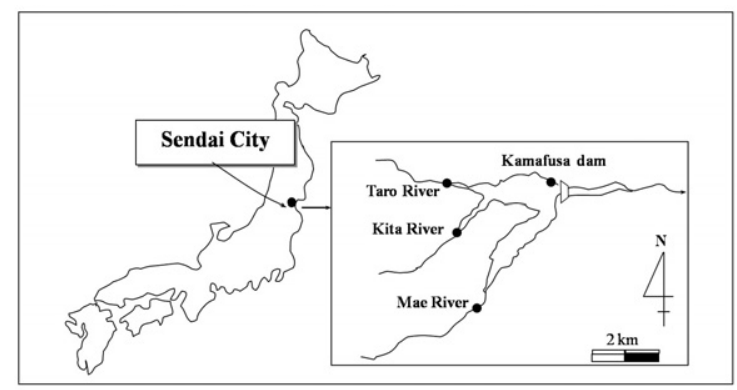

Fig. 1. The locations of the sampling points.

\subsection{AOC Determination}

The determination of AOC has been developed to measure the potential for bacterial regrowth, based on the measurement of the maximum extent of growth of a selected pure bacteria culture in representative water samples in which the indigenous bacteria have been killed or inactivated by heat treatment. Colony counts are used for determining bacterial densities. The analytical method developed by van der Kooij[6] was adopted in the present study. The method employs Pseudomonas fluorescens strain P17 (ATCC49642) and Spirillum species strain NOX (ATCC49643). These two microorganisms prefer different groups of compounds. P17 has a great nutritional versatility, and is able to grow on a variety of carbohydrates, aromatic acids and amino acids; whereas, NOX cannot utilize carbohydrates, alcohols or aromatic acids, but able to take advantage of a wide range of carboxylic acids. Strain NOX can also utilize a few amino acids; however, it is unable to assimilate amino acids when grown on mixtures of compounds[6]. All glassware was thoroughly cleaned and rendered organic carbon-free by combustion at $550^{\circ} \mathrm{C}$ for 1 hour. The samples were incubated at $15^{\circ} \pm 0.5^{\circ} \mathrm{C}$, with the number of colony forming units (CFU) measured in 9 petri-dishes per water sample after 7, 9, and 11 days. The colonies were measured on R2A agar using the plate count technique after $72^{\circ} \pm 3$ hours of incubation at $28^{\circ} \pm 1^{\circ} \mathrm{C}$. The total AOC, in micrograms per liter of equivalent acetate-carbon, is the sum of AOC-P17 and AOC-NOX. In the present study, the yield coefficients of AOC-P17 and AOC-
NOX were $4.1^{\circ} \times 106$ and $1.2^{\circ} \times 10^{7} \mathrm{CFU} / \mu$ g acetate-carbon, respectively.

\subsection{Algal Culture}

The blue-green algae, Phormidium tenue (ATCC49642), was selected as the test alga to form AOM, and cultivated in an incubator under illumination conditions of 3,000 lx, with a 12 $\mathrm{hrs} / 12 \mathrm{hrs}$ light/dark cycle at a temperature of $22^{\circ} \mathrm{C}$. P. tenue was cultured with two different culture media i.e. the M-11 culture medium and the CT culture medium. Table 1 shows the components of each culture medium.

Table 1. The components of culture media

\begin{tabular}{|c|c|c|c|}
\hline \multicolumn{2}{|c|}{ M-11 culture medium } & \multicolumn{2}{|l|}{ CT culture medium } \\
\hline $\mathrm{NaNO}_{3}$ & $10 \mathrm{mg}$ & $\mathrm{Ca}\left(\mathrm{NO}_{3}\right)_{2} \cdot 4 \mathrm{H}_{2} \mathrm{O}$ & $15 \mathrm{mg}$ \\
\hline $\mathrm{K}_{2} \mathrm{HPO}_{4}$ & $1 \mathrm{mg}$ & $\mathrm{KNO}_{3}$ & $10 \mathrm{mg}$ \\
\hline $\mathrm{MgSO}_{4} \cdot 7 \mathrm{H}_{2} \mathrm{O}$ & $7.5 \mathrm{mg}$ & $\beta$ - $\mathrm{Na}_{2}$ glycerophosphate $\cdot 5 \mathrm{H}_{2} \mathrm{O}$ & $5 \mathrm{mg}$ \\
\hline $\mathrm{CaCl}_{2} \cdot 2 \mathrm{H}_{2} \mathrm{O}$ & $4 \mathrm{mg}$ & $\mathrm{MgSO}_{4} \cdot 7 \mathrm{H}_{2} \mathrm{O}$ & $4 \mathrm{mg}$ \\
\hline $\mathrm{Na}_{2} \mathrm{CO}_{3}$ & $3 \mathrm{mg}$ & Vitamin $B_{12}$ & $0.01 \mu \mathrm{g}$ \\
\hline $\mathrm{FeSO}_{4} \cdot 7 \mathrm{H}_{2} \mathrm{O}$ & $0.1 \mathrm{mg}$ & Biotin & $0.01 \mu \mathrm{g}$ \\
\hline $\mathrm{Na}_{2} \mathrm{EDTA} \cdot 2 \mathrm{H}_{2} \mathrm{O}$ & $0.1 \mathrm{mg}$ & Thiamine $\mathrm{HCl}$ & $1 \mu \mathrm{g}$ \\
\hline Distilled water & $100 \mathrm{~mL}$ & PIV metals & $0.3 \mathrm{~mL}$ \\
\hline \multirow[t]{3}{*}{$\mathrm{pH}$} & 8.0 & TAPS & $40 \mathrm{mg}$ \\
\hline & & Distilled water & $99.7 \mathrm{~mL}$ \\
\hline & & $\mathrm{pH}$ & 8.2 \\
\hline
\end{tabular}

\subsection{Chlorine Oxidation}

Sodium hypochlorite ( $\mathrm{NaOCl}$ ) solution was standardized by titration, and then diluted with distilled water. The chlorine doses were set at $0,2,5,10,20$, and $30 \mathrm{mg} / \mathrm{L}$. Sealed $3 \mathrm{~L}$ amber glass bottles were used for the chlorine oxidation experiment. The amber glass bottles were also covered with aluminum foil to prevent photodegradation of the solutions. The contents of amber glass bottles were stirred continuously with a magnetic stirrer. After chlorine oxidation, a sample was withdrawn from each bottle, and then filtered through a GF/C filter and the reaction terminated by the addition of sodium thiosulfate immediately after collection.

\subsection{Ultra Filtration}

The samples were initially filtered through a Whatman GF/F filter and then subjected to ultra filtration (Regenerated cellulose PL, Ultra filtration membranes; MILLIPOERK, USA). The samples were fractionated into 4 fractions by molecular weight (lower than 1,000 Da, 1,000-5,000 Da, 5,000-10,000 Da, and higher than 10,000 $\mathrm{Da})$.

\section{Results and Discussion}

\subsection{Seasonal Variation of AOC in Dam and River}

Fig. 2 shows the AOC concentrations at each sampling point. The AOC concentration of the Kamafusa dam ranged from 111 to $305 \mu \mathrm{g} / \mathrm{L}$; where as those for the three rivers flowing into the dam ranged from 34 to $293 \mu \mathrm{g} / \mathrm{L}$. The average AOC concentration of Kamafusa dam was $178 \mu \mathrm{g} / \mathrm{L}$, approximately 1.6 times higher than 


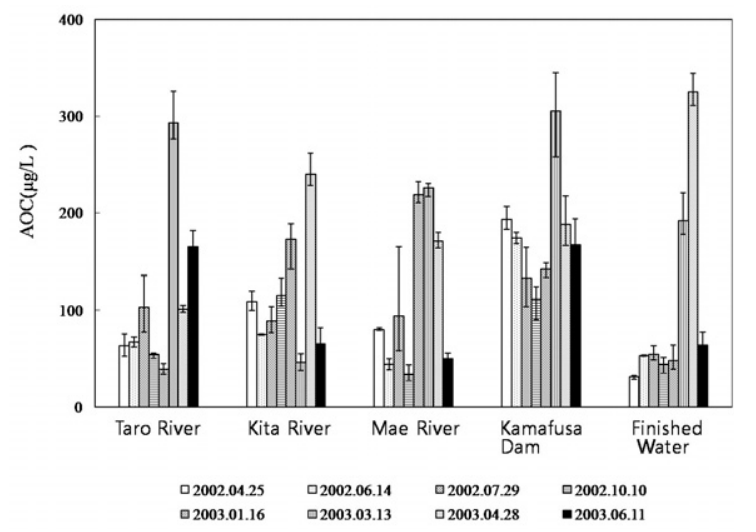

Fig. 2. The variation in the assimilable organic carbon (AOC) concentrations at each sampling point.

that of the rivers, meaning that the AOC concentration of the Kamafusa dam tended to be higher than that of each river ( $t$-test, $p<0.01)$. The finished water had an average AOC concentration of $107 \mu \mathrm{g} / \mathrm{L}$. Unexpectedly, the AOC concentration of the finished water on April 28th, 2003 was higher than that of the Kamafusa dam, which was considered to be due to contamination by organic substances from the exchange of sand after rapid sand filtration. Except for the sample taken on April 28th, 2003, the AOC concentration of the finished water was lower than that of the Kamafusa dam, and the average AOC concentration was about $50 \mu \mathrm{g} / \mathrm{L}$. The maximum AOC concentration was observed in spring; March or April, at all survey points. Fig. 3 shows the ${ }^{\circ}$ average ratio of AOC-P17 to AOC-NOX at each survey point. In the case of the surface water, such as rivers and dams, the AOC-P17 component accounted for $82-93 \%$ of the total AOC concentration, while in the finished water, the AOC-P17 component was $57 \%$. It was obvious that the increase in the AOCNOX component was due to the production of AOC-NOX due to chlorine oxidation.

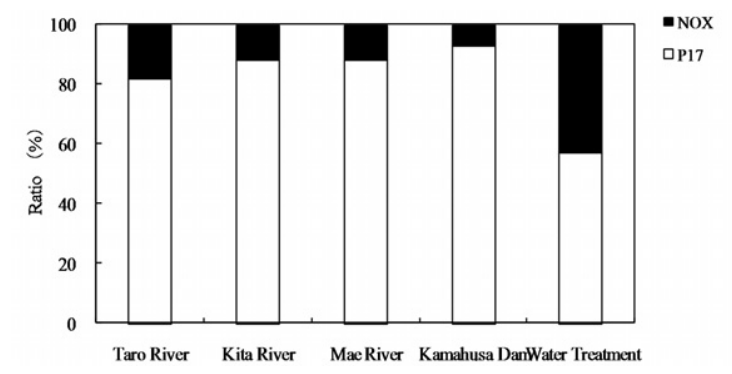

Fig. 3. The ratio of assimilable organic carbon (AOC)-P17 to AOCNOX.

\subsection{Relation between $A O C$ and Algae}

In order to understand the increase in the AOC concentration in the Kamafusa dam, the relationship between the AOC concentration and algal cell numbers [16] was investigated (shown in Fig. 4). The seasonal change of the algal cell numbers showed a similar tendency to that of the seasonal changes in the AOC concentration. The algal cell numbers increased in spring

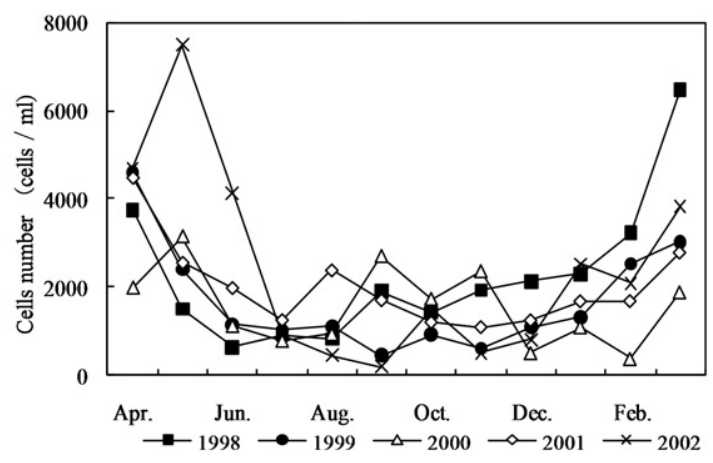

Fig. 4. The variation in the algal cell numbers at the Kamafusa dam.

and decreased in autumn. An average cell number of about 4,700 cells/mL was observed in spring, which was over 2 times greater than those of the other seasons. From these results, it was considered that algal growth could have caused the increase in the AOC concentration. Therefore, the effect of algal growth on the variation in the AOC concentration was investigated.

\subsection{Effect of Algal Growth on AOC}

P. tenue, one of the dominant species in the Kamafusa dam, was selected and cultured with M-11 and CT culture media. The variation in the $P$. tenue cell numbers in each culture medium is shown in Fig. 5. The initial cell numbers of P. tenue in the M-11 and CT culture media were $0.8 \times 10^{4}$ and $1 \times 10^{4}$ cells per $\mathrm{mL}$, respectively. The cell numbers increased rapidly in each culture medium, and on the 39th the cell numbers in the M-11 and CT culture media increased to $67 \times 10^{4}$ and $115 \times 10^{4}$ cells per $\mathrm{mL}$, respectively. On the 68th day, the cell numbers in each of the culture media were $90 \times 10^{4}$ and $102 \times 10^{4}$ cells per $\mathrm{mL}$, respectively. Fig. 6 shows the variation in the DOC and AOC concentrations produced by $P$. tenue during culturing in the M-11 culture medium. The DOC concentration in the M-11 culture medium before inoculating with $P$. tenue was about $1.5 \mathrm{mg} / \mathrm{L}$. The DOC concentration had a tendency to increase with time. At the stationary phase, after the 39th day, the DOC concentration increased to $9.2 \mathrm{mg} / \mathrm{L}$. The AOC concentration in the M-11

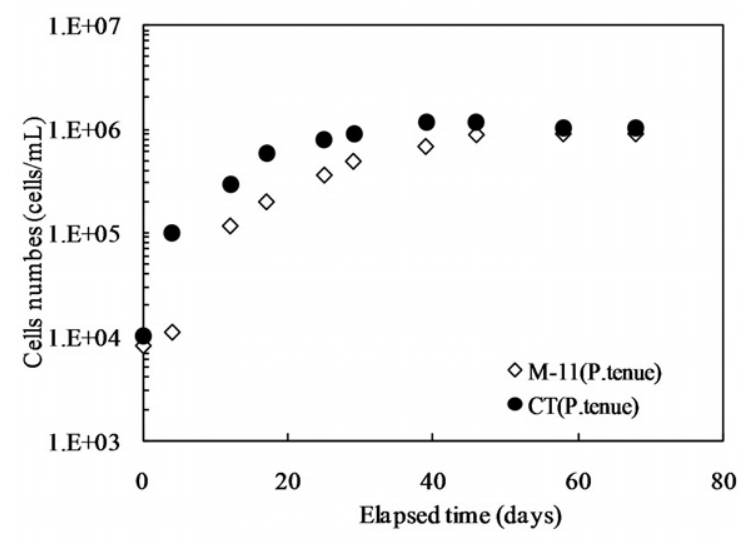

Fig. 5. The variation in the Phormidium tenue cell numbers in each culture medium. 


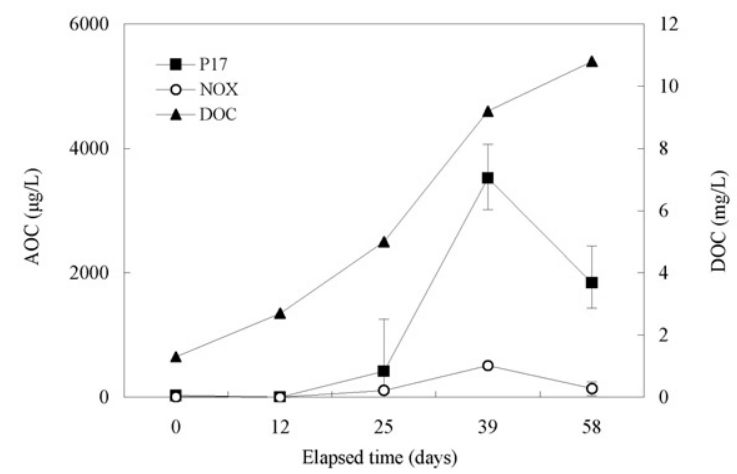

Fig. 6. The variation in the dissolved organic carbon (DOC) and assimilable organic carbon (AOC) concentrations (M-11 culture medium).

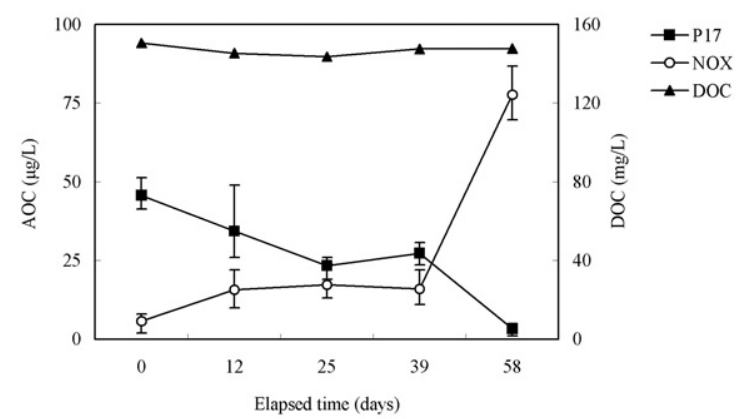

Fig. 7. The variation in the dissolved organic carbon (DOC) and assimilable organic carbon (AOC) concentrations (CT culture medium).

culture medium before inoculating with $P$. tenue was $39 \mu \mathrm{g} / \mathrm{L}$. The AOC concentration increased significantly during the latter half of the logarithmic phase to about $4,000 \mu \mathrm{g} / \mathrm{L}$ during the stationary phase, of which the AOC-P17 component occupied at least $90 \%$. In other words, the variation in the AOC concentration was dependent on the AOC-P17 component. Fig. 7 shows the variation in the DOC and AOC concentrations produced by $P$. tenue during culturing in the CT culture medium. The DOC concentration in the CT culture medium was much higher than

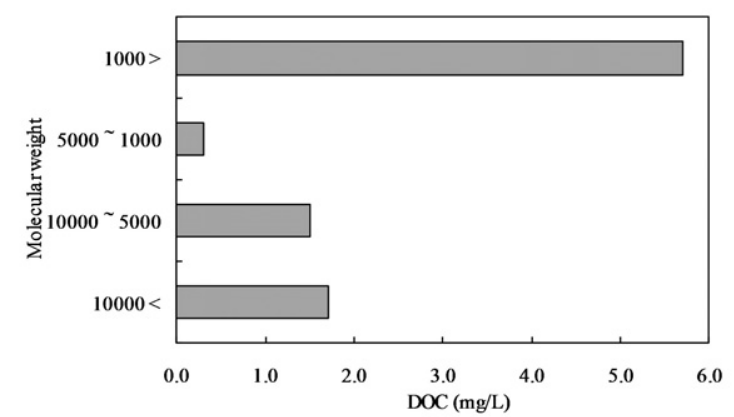

Fig. 8. Fractionation of the dissolved organic carbon (DOC) by ultrafiltration (EOM, M-11 culture medium). EMC:extracellular organic matter.

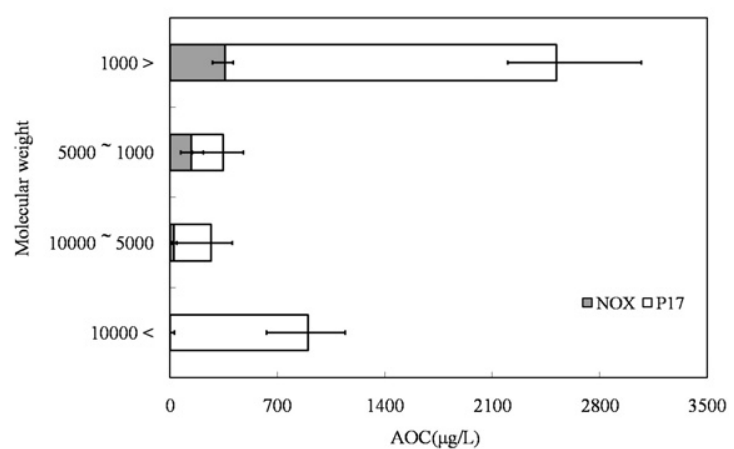

Fig. 9. Fractionation of the assimilable organic carbon (AOC) by ultrafiltration rbon.

that in the M-11 culture medium. The DOC concentration, which did not change throughout the culture period averaged $152 \mathrm{mg} / \mathrm{L}$. In contrast to the M-11culture medium, the CT culture medium did not lead to a significant variation in the AOC concentration. The maximum AOC concentration during the culture period was about $80 \mu \mathrm{g} / \mathrm{L}$. These results indicated that the generation of AOC from algae was greatly influenced by the culture medium. It was considered that the generation of AOC actively occurred when the concentration of organic substances in water due to the presence of algae was relatively low. To investigate the AOC and DOC concentration profiles derived from EOM during the stationary phase, the EOM was fractionated by ultra filtration into 4 fractions by molecular weight (Fig. 8). The DOC produced by EOM was observed to be mainly under a molecular weight of 1,000 Da. The ratio of DOC under 1,000 Da was over $60 \%$ of the total DOC concentration. As shown in Fig. 9, the AOC produced by P. tenue was also detected mainly in the fraction lower than 1,000 Da. Although AOC-NOX accounted for $20 \%$ of the total AOC in this fraction, no AOC-NOX was detected in molecular weight fraction over 10,000 Da.

\subsection{Effect of Chlorination on AOC Included in AOM}

Fig. 10 shows the relationship between the chlorine dose and residual chlorine for EOM and IOM. The chlorine demand for the oxidation of EOM and IOM (P. tenue, M-11 culture medium) was

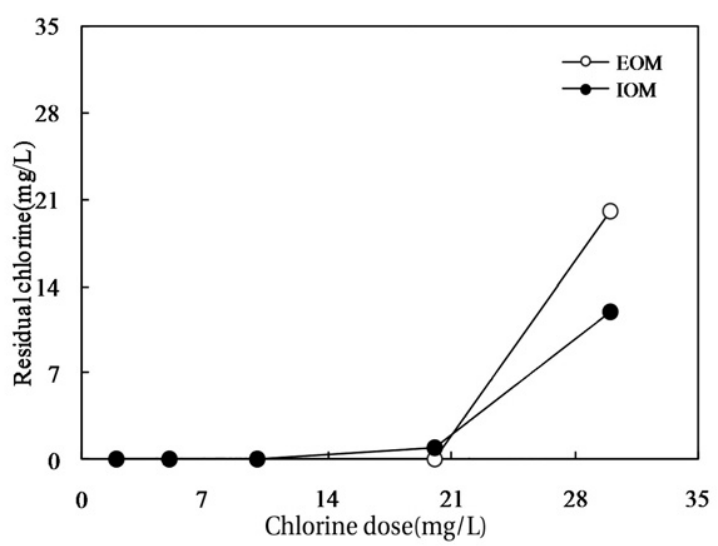

Fig. 10. The relationship between chlorine dose and residual chlorine. 

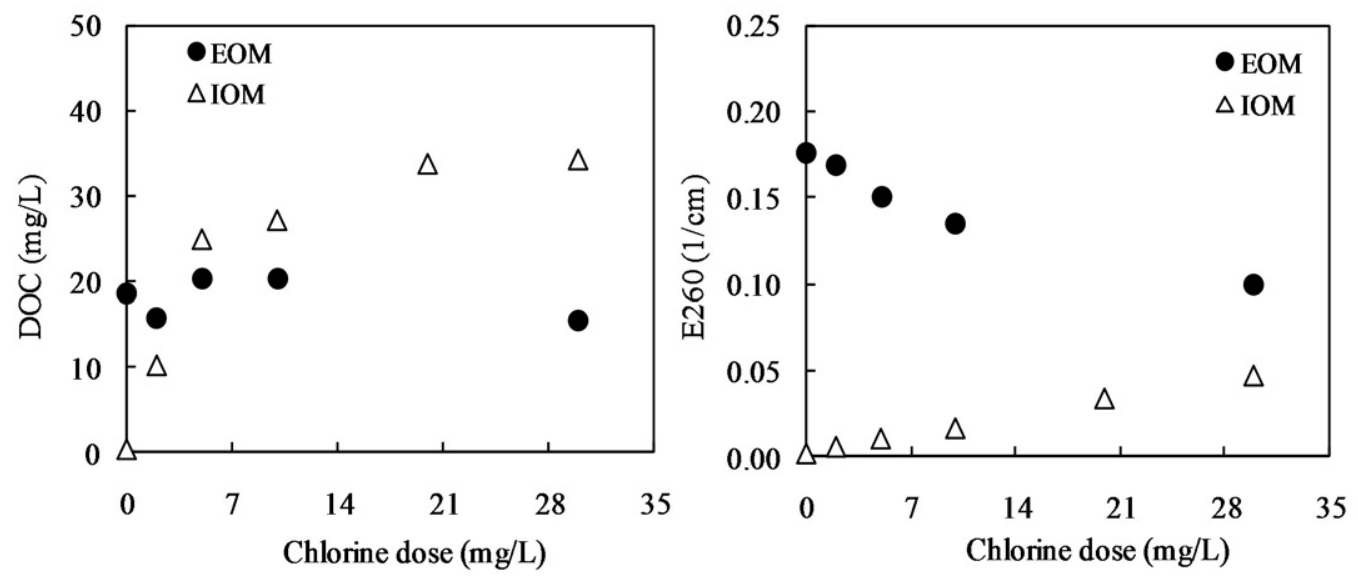

Fig. 11. Variation in the dissolved organic carbon (DOC) and E260 with chlorine dose.

about $20 \mathrm{mg} / \mathrm{L}$ for both. With fresh culture medium, no chlorine was consumed. Fig. 11 shows the variation in the DOC and UV absorbance at $260 \mathrm{~nm}$ (E260) on chlorine oxidation of EOM and IOM. With fresh culture medium, the DOC concentration and E260 did not significantly changed with increasing chlorine dose (DOC, 0.7-0.9 mg/L; E260, 0.019-0.023 $\mathrm{cm}^{-1}$ ). However, the E260 of EOM had a tendency to decrease with increasing chlorine dose.

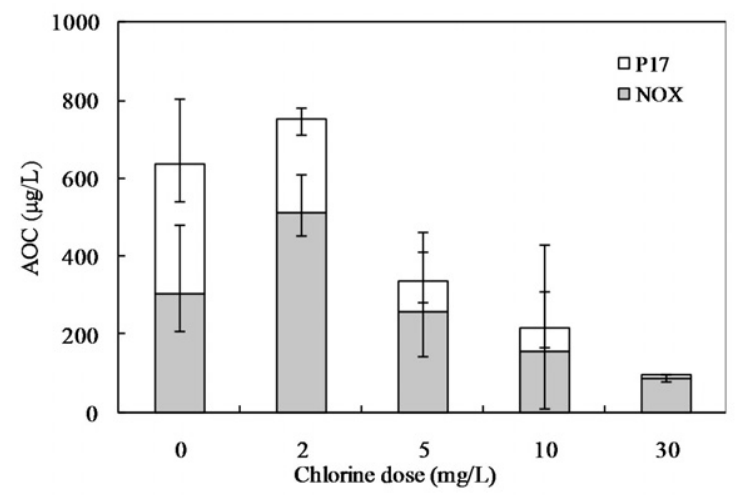

Fig. 12. Variation in the assimilable organic carbon (AOC) concentrations after chlorine oxidation (EOM).

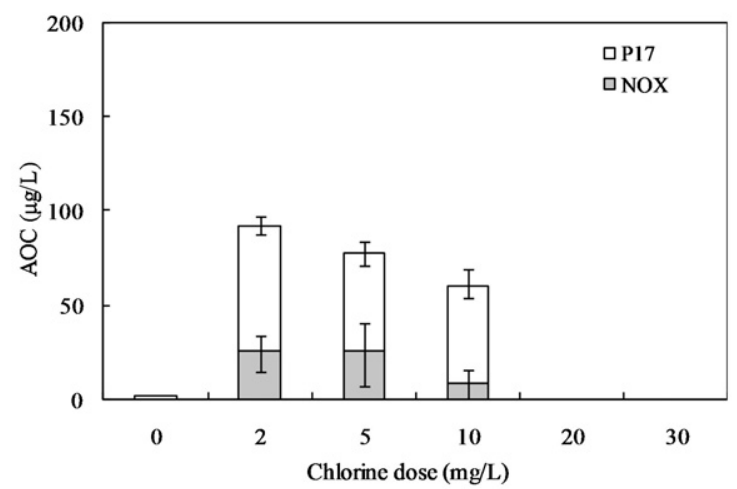

Fig. 13. Variation in the assimilable organic carbon (AOC) concentrations after chlorine oxidation (IOM).
For the IOM, the DOC concentration and E260 increased with increasing chlorine dose. The increases in the DOC and E260 due to chlorination were due to the release of dissolved AOM from the destruction of algal cells. Although the E260 increased due to chlorine oxidation, the maximum value was not higher than that of the EOM. Fig. 12 shows the variation in the AOC concentration during the chlorine oxidation experiment with EOM. Although the AOC concentration increased by $18 \%$ with the low chlorine dose $(2 \mathrm{mg} / \mathrm{L})$, it was found to decrease with increasing chlorine dose over $5 \mathrm{mg} / \mathrm{L}$. A chlorine dose of $5 \mathrm{mg} / \mathrm{L}$ resulted in a decrease in the AOC concentration from 636 to $336 \mu \mathrm{g} / \mathrm{L}$. With 10 and $30 \mathrm{mg} / \mathrm{L}$ chlorine doses, the AOC concentration further decreased to 219 and $98 \mu \mathrm{g} / \mathrm{L}$, respectively. The ratio of AOC-P17 to AOC-NOX for the EOM before chlorine oxidation was about $50 \%$. With increasing chlorine dose, the AOC-P17 component significantly decreased, and the portion of the AOC-NOX component increased. When residual chlorine was detected after a chlorine dose of $30 \mathrm{mg} / \mathrm{L}, 98 \mu \mathrm{g} / \mathrm{L}$ of AOC still remained, which would be insufficient to prevent bacterial regrowth. To treat the AOC included in the EOM, it was considered that a great than usual chlorine dose may be needed. Furthermore, in order to clarify the effect of chlorination on the AOC of IOM, chlorine oxidation of IOM was performed, the results of which are shown in Fig. 13. IOM was collected by centrifugation of algae cells. With a chlorine dose of $0 \mathrm{mg} / \mathrm{L}$, the AOC concentration in the IOM was about $2 \mu$ $\mathrm{g} / \mathrm{L}$. However, the AOC concentration increased with increasing chlorine dose. The AOC concentration increased to $92 \mu \mathrm{g} / \mathrm{L}$ after oxidation with a chlorine dose of $2 \mathrm{mg} / \mathrm{L}$. In the cases of chlorine doses of 20 and $30 \mathrm{mg} / \mathrm{L}$; however, no AOC was detected. The ratio of AOC-P17 to AOC-NOX differed from that for EOM. The AOC-P17 component was higher than that of AOC-NOX, with a ratio above $74 \%$ for each chlorine dose. From this result, it was found that the AOC included in IOM could be sufficiently removed when usual chlorination was performed.

\section{Conclusions}

Our interest has been in the variation of the AOC concentration in drinking water resources. In present study, a field survey at the Kamafusa dam, the drinking water resource of Sendai city, Japan, as well as the three inflowing rivers, was conducted over a 14 month period. The higher AOC concentration in the Kamafusa 
dam compared with those of the three rivers indicated that eutrophication could cause changes in the AOC concentration. The algae appeared to be an important factor relating to the variation in the AOC concentration. To understand the effect of algae on the AOC concentration, how the AOC was produced due to algal growth and varied with chlorination was investigated. The AOC included in EOM could be formed in large amounts by algae grown in fresh culture medium, including organic substances, such as in the M-11 culture medium. This result implied that a lower concentration of an organic substance could actively stimulate algal metabolism. The EOM produced by $P$. tenue with a molecular weight lower than 1,000 Da would help the formation of AOC. The experiments on the chlorine oxidation of EOM and IOM revealed that the AOC included in EOM was difficult to remove by chlorination, although the AOC included in IOM could be removed under conditions where residual chlorine was detected.

\section{Acknowledgements}

This work was financially supported by the Korea Ministry of Environment (EOM) as the ET-Human resource development project.

\section{References}

1. Levhevallier M, Christian V, Kimberly B, Eva I, Debbie V. Impact of enhanced and optimized coagulation on removal of organic matter and its biodegradable fraction in drinking water. Water Res. 2000;34:3247-3257.

2. Volk C, Dundore E, Schiermann J, Lechevallier M. Practical evaluation of iron corrosion control in a drinking water distribution system. Water Res. 2000;34:1967-1974.

3. Tsai YP, Pai TY, Qiu JM. The impacts of the AOC concentration on biofilm formation under higher shear force condition. $J$. Biotechnol. 2004;111:155-167.

4. Liu W, Wu H, Wang Z, Ong SL, Hu JY, Ng WJ. Investigation of assimilable organic carbon (AOC) and bacterial regrowth in drinking water distribution system. Water Res. 2002; 36:891-898.

5. Huang WJ, Fang GC, Wang CC. The determination and fate of disinfection by-products from ozonation of polluted raw water. Sci. Total Environ. 2005;345:261-272.

6. Vanderkooij D. Assimilable organic-carbon as an indicator of bacterial regrowth. J. Am. Water Works Assoc. 1992;84:5765 .

7. Vanderkooij D, Veenendaal HR, Baarslorist C, Vanderklift DW, Drost YC. Biofilm formation on surfaces of glass and teflon exposed to treated water. Water Res. 1995;29:16551662.

8. Escobar IC, Randall AA. Assimilable organic carbon (AOC) and biodegradable dissolved organic carbon (BDOC): Complementary measurements. Water Res. 2001;35:44444454 .
9. Lehtola MJ, Miettinen IT, Vartiainen T, Martikainen PJ. Changes in content of microbially available phosphorus, assimilable organic carbon and microbial growth potential during drinking water treatment processes. Water Res. 2002;36:3681-3690.

10. Schmidt W, Hambsch B, Petzoldt H. Classification of algogenic organic matter concerning its contribution to the bacterial regrowth potential and by-products formation. Water Sci. Technol. 1998;37:91-96.

11. Hammes F, Meylan S, Salhi E, Koster O, Egli T, Von Gunten U. Formation of assimilable organic carbon (AOC) and specific natural organic matter (NOM) fractions during ozonation of phytoplankton. Water Res. 2007;41:1447-1454.

12. Plummer JD, Edzwald JK. Effect of ozone on disinfection byproduct formation of algae. Water Sci. Technol. 1998;37:4955.

13. Hem LJ, Efraimsen H. Assimilable organic carbon in molecular weight fractions of natural organic matter. Water Res. 2001;35:1106-1110.

14. Charnock C, Kjonno O. Assimilable organic carbon and biodegradable dissolved organic carbon in Norwegian raw and drinking waters. Water Res. 2000;34:2629-2642.

15. Escobar IC, Randall AA. Sample storage impact on the assimilable organic carbon (AOC) bioassay. Water Res. 2000;34:1680-1686.

16. Report of the investigation of water quality, Sendai City Reports (1998-2002). 2003;1-270. 